\title{
A PRODUÇÃO FAMILIAR NO/DO CERRADO E SUAS REPRESENTAÇÕES TERRITORIAIS: as comunidades rurais no município de Catalão (GO)
}

\author{
THE FAMILIAR PRODUCTION IN/OF THE SAVANNAH AND ITS \\ REGIONAL REPRESENTATIONS: the rural communities in Catalão city \\ (GO)
}

\author{
LA PRODUCTION FAMILIALE EN/DU “CERRADO” ET SES \\ REPRÉSENTATIONS DÊS TERRITOIRES: les communautes rurales dans \\ la municipalite de Catalão (GO)
}

\author{
Estevane de Paula Pontes Mendes \\ Professora Doutora do Programa de Pós-Graduação em Geografia da Universidade Federal de \\ Goiás, Campus Catalão. Núcleo de Estudos e Pesquisas Sócio-Ambientais (NEPSA/CNPq). \\ Av. Dr. Lamartine Pinto de Avelar, 1120 Setor Universitário \\ 75704-020 - Catalão (GO) \\ E-mail: iemendes@ibest.com.br
}

\section{Resumo}

Este texto propõe uma análise em torno do comportamento sociocultural, econômico e organizacional de comunidades rurais que utilizam o território como espaço produtivo, para constituição de seu patrimônio familiar e para estruturação de um espaço de trabalho da família, salientando os comportamentos comuns dos membros das comunidades e das numerosas características de crença que constituem o modo de vida rural, sob uma percepção do espaço de vivência. Todas as dimensões da existência se realizam no território a partir de uma relação interativa e completiva. Assim, os vínculos afetivos são criados na relação do trabalho do homem sobre uma base geográfica. Essas discussões avigoram, ainda mais, a necessidade de conhecimento e preservação da identidade cultural de indivíduos ligados entre si por laços de parentesco e de consangüinidade. A história de cada família evidencia os valores compartilhados num dado espaço social.

Palavras-chave: Território. Cultura. Comunidades rurais. Catalão (GO).

\section{Abstract}


This text proposes an analysis about the sociocultural, economical and orgazitional behavior or rural communities that have been used the territory as a productive space, to the constitution of their familiar assets and for the struction of a space of the family's work, giving importance to the ordinary behaviors of communities members and to the numerous characteristics of belief that constitutes the way of rural life, under a perception of vivency. All the dimensions of the existence are achieved in the territory from an interactive and completive relation. Like this, the affective bonds are created in the relation of men's work upon a geographical basis. These discussions heighten, moreover, the necessity of knowledge and preservation of individual's cultural identity between each other by relationship and by flesh and blood. Each family's history shows up the doubled up values in a given social space.

Key-words: Territory. Culture. Rural communities. Catalão (GO).

\section{Résumé}

Ce texte présente une analyse autour du comportement socio-culturel, économique et organisationnel de communautés rurales qui utilisent le territoires comme espace productif, pour la constitution de son patrimoine familial et pour la structuration d'un espace de travail de la famille, en soulignant les comportements communs des membres des communautés et des nombreuses caractéristiques de croyance qui constituent le mode de vie rural, sous une perception de l'espace de familiarité. Toutes les dimensions de l'existence si réalisent dans le territoire à partir d'une relation interactive et complétive. Ainsi, les attaches affectives sont crées dans la relation du travail de l'homme sur une base géographique. Ces discussions fortifient, encore plus, la nécessité de connaissance et de préservation de l'identité culturelle de l'individus liés entre eux par liens de parentes et de consanguinité. L'histoire de chaque famille confirme les valeurs partagées dans un donné espace social.

Mots-clés: Terrtoire. Culture. Communautes rurales. Catalão (GO).

\section{Introdução}

[...] A exploração familiar não é [...] um elemento da diversidade, mas contém nela mesma toda esta diversidade. Em um mesmo lugar e em um mesmo modelo de funcionamento, as explorações dividem-se em diferentes classes sociais segundo suas condições objetivas de produção (superfície, grau de mecanização, nível técnico, capacidade financeira). Por exemplo, em uma mesma comunidade, as explorações do tipo Camponês podem ser mais ou menos importantes [...]. (Lamarche, 1993)

Analisar o campo como território permite compreendê-lo como espaço de vida onde se materializam todas as dimensões da existência humana. A cultura, a produção, o trabalho, a organização política são relações sociais constituintes das dimensões territoriais. Todas essas dimensões se realizam no território a partir de uma relação

Ateliê Geográfico Goiânia-GO $\quad$ v. 3,n.1 $a b r / 2009 \quad$ p.44-68 página 45


interativa e completiva. Nesse sentido, os territórios são espaços geográficos e políticos onde os atores sociais realizam seus projetos de vida. O espaço social é a materialização da existência humana, constituindo uma dimensão da realidade. Assim, a configuração territorial é formada pelos elementos da natureza e pelas dimensões sociais, produzidas pelas relações entre as pessoas, como a cultura, a política e a economia.

A vida simples das famílias rurais revela um dos mundos manifestos como resultado de uma espacialidade construída por interesses divergentes. Nesse sentido, o estudo das comunidades rurais exige considerar as relações que interligam as famílias (unidade de produção, consumo e convívio) e os valores contidos nessa relação. A compreensão da reprodução de seu modo de vida é buscada através das relações de parentesco, da multifuncionalidade de tarefas, das formas de cooperação e de solidariedade entre parentes e vizinhos e demais particularidades inerentes à própria construção do espaço social. Tudo isso quer dizer, em síntese, que são bem diversas as combinações entre os vários tipos de atividades econômicas e vínculos sociais que permitem a sobrevivência dessa população.

A trajetória da pesquisa envolveu, além da revisão da literatura pertinente à temática, levantamento, sistematização, análise e representação de dados e informações de fontes primárias e secundárias. A pesquisa empírica propiciou o conhecimento de concepções e representações da riqueza sociocultural do lugar (seu modo de vida), como a história das famílias, da região, dos 'causos' e, principalmente, da utilização do tempo, o ritmo de vida e a sua inserção na ordem social como um todo. Dessa forma, buscou-se compreender o espaço social através da constituição da história do lugar por meio de fontes orais e documentais, o que lhes confere uma identidade própria.

A pesquisa foi realizada no município de Catalão, de 2000 a 2007, nas seguintes comunidades rurais: Coqueiro (38 sedes/residências), Mata Preta (64 sedes/residências), Ribeirão (72 sedes/residências) e Morro Agudo/Cisterna (79 sedes/residências). Essa região está localizada no sudeste do Estado de Goiás, abrangendo uma área de $3.777,6 \mathrm{~km}^{2}$ (IBGE - Censo, 2000), o que corresponde a 1,11\% do território goiano. As comunidades rurais, escolhidas para a pesquisa empírica, localizam-se na parte noroeste do município, distando, aproximadamente, entre $15 \mathrm{~km}$ a $60 \mathrm{~km}$ da sede municipal. O acesso às comunidades rurais se dá por estradas vicinais e, principalmente, pela BR-050 no sentido Catalão - Brasília. 
O móvel desse estudo assenta-se na análise do comportamento sociocultural, econômico e organizacional de comunidades rurais que utilizam o território como espaço produtivo, para constituição de seu patrimônio familiar e para a estruturação de um espaço de trabalho da família. Algumas características compõem o núcleo genérico dentre os vários conceitos, como a família enquanto proprietária dos meios de produção, o trabalho na terra e os valores e tradições que constituem o patrimônio sociocultural.

Como meio de sobreviver, essas unidades produtivas lançam mão de uma série de combinações produtivas agrícolas e não-agrícolas e uso de formas de trabalho nãoassalariadas, o que tem permitido sua inserção aos mercados. Essas manifestações socioculturais e econômicas organizam-se em reação à imposição das formas capitalistas, o que nos leva a questionar as noções de atraso, determinismo e funcionalidade. A reprodução desse modo de vida deve ser compreendida a partir da valorização dos recursos disponíveis em seus estabelecimentos (valorização do patrimônio sociocultural) e de sua integração com o mercado. Todos os esforços centram-se em garantir a produção de um lugar de vida e de trabalho capaz de preservar a memória da família e de reproduzi-la. Esse uso múltiplo de uma mesma base geográfica caracteriza a sua territorialidade.

\section{A produção social do território}

Observa-se que cada 'lugar' apresenta condições diferenciadas, que promovem ou dificultam determinadas manifestações culturais. É através da forma como se dá a inserção das comunidades rurais na sociedade que lhe atribui um caráter geral e específico no seio de uma sociedade. As reflexões apresentadas mostram que a relação estabelecida entre a propriedade, o trabalho e a família sugere uma diversidade de situações particulares que definem suas estratégias de reprodução e sua inserção na sociedade. A determinação de suas decisões, também, leva em conta as formas de vida local que revelam sua história, suas tradições, seus valores morais e suas ambições. Nessa perspectiva, surgem vários espaços, como o social, o político, o econômico, o ideológico e o cultural, dentre outros, que permitem a reprodução de segmentos sociais diferenciados na produção do território. Assim, a forma espacial aparece como resultado das forças contraditórias de interesses que a produziu. 
O lugar é um produto das relações humanas e entre o homem e a natureza, construído por relações sociais que se realizam no plano vivido, o que garante a construção de uma rede de significados e sentidos que são produzidos pela história e pela cultura de uma dada sociedade, constituindo identidade, uma vez que é nesse espaço que o homem se reconhece porque é o lugar da vida. "O sujeito pertence ao lugar como este a ele, pois a produção do lugar liga-se indissociavelmente à produção da vida. [...]. Cada sujeito se situa num espaço concreto e real onde se reconhece ou se perde, usufrui e modifica, posto que o lugar tem usos e sentidos em si." (CARLOS, 1996, p. 29). Nessa perspectiva, é através da compreensão do lugar que passamos a perceber o mundo e ajustamos nossa interpretação, pois nele o permanente e o real se realizam sobre o movimento, o passageiro e o imposto de fora. Nesse sentido, Santos (1994, p. 37) diz que "o espaço aparece como um substrato que acolhe o novo, mas resiste às mudanças, guardando o vigor da herança material e cultural, a força do que é criado de dentro e resiste, força tranqüila que espera, vigilante, a ocasião e a possibilidade de se levantar."

O morador das comunidades é um produtor que combina os meios de produção com seu próprio trabalho e tem domínio das condições técnicas de sua produção. A relação entre trabalho e produção, no núcleo doméstico, possibilita a diferenciação demográfica interna entre as unidades econômicas familiares, com o crescimento da produtividade do trabalho (MARX, 1998). Tal particularidade permitiu a vitalidade da inserção dos agricultores familiares na sociedade capitalista. Esse processo promove transformação das formas de ocupação da força de trabalho, introduzindo mudanças sociais e culturais que sobrepõem às formas tradicionais de mercado de trabalho.

Diante das particularidades inerentes às dimensões do patrimônio herdado pelos atuais agricultores familiares no Brasil, Tedesco (2001, p. 11) ressalta que alguns elementos da generalidade do conceito conferem atributos comuns, como "[...] a família como proprietária dos meios de produção, o trabalho na terra, modalidades de produção e manifestações de valores e tradições (patrimônio sociocultural) em torno da e para a família." Os debates promovidos no final da década de 1980 procuravam estabelecer uma reflexão acerca das características e particularidades do processo de desenvolvimento do capitalismo no campo. Em um segundo momento, buscam analisar os motivos da gradativa redução da população rural, principalmente dos pequenos 
produtores, assim como a natureza sociocultural, as estratégias de desenvolvimento e suas características determinantes. Desse modo, o novo enfoque das discussões assentase na diversidade e na diferenciação que as formas familiares de produção na agricultura assumiram nas sociedades contemporâneas.

Brumer et al. (1993) contribui com esta discussão ao considerar a "exploração familiar" como um objeto de estudo em si, um conceito de análise necessário para a compreensão do funcionamento e da evolução das formas sociais de produção agrícola. Destarte, coloca-se a coexistência de diversos modelos de funcionamento, considerando que a "exploração familiar" não pode ser definida como um 'modo de produção' específico e, nem como um grupo social homogêneo [no sentido marxista do termo], como é o caso da exploração camponesa ou da empresa de produção. "A 'exploração familiar' é ao mesmo tempo uma memória, uma situação, uma ambição e um desafio. [...].” (LAMARCHE, 1993, p. 22).

A abordagem de Wanderley (2001) valoriza as estratégias de produção das unidades familiares que se baseiam na valorização dos recursos disponíveis no estabelecimento familiar e destinam-se a assegurar a sobrevivência da família e a de sua exploração no presente e no futuro.“[...] De uma certa forma, os agricultores familiares modernos enfrentam os novos desafios com as armas que possuem e que aprenderam a usar a partir de sua experiência." (WANDERLEY, 2001, p. 35, grifos da autora).

A produção rural assentada no trabalho familiar deve ser analisada em seu conjunto, levando-se em conta as diversas entidades que a estruturam, como sua organização interna e o grau de inserção no mercado. A análise do funcionamento dessas unidades produtivas sugere considerar as diferentes lógicas em função das quais o produtor determina suas escolhas fundamentais. Essas unidades de produção conciliam a propriedade, o trabalho e a família. A interdependência estabelecida entre esses três fatores orienta sua dinâmica de reprodução, incidindo diretamente sobre a transmissão do patrimônio, a reprodução do grupo familiar, a produção do saber produzir (experiência), o processo de trabalho e o valor da terra.

Esses elementos são considerados essenciais para o estudo da estrutura dessas unidades de produção e sua adaptação frente às condições de mercado. No dizer de Wanderley (2001) essa realidade impõe à família a necessidade de ser plenamente responsável pelos seus projetos, seu programa de trabalho e sua disciplina mediante sua 
sujeição à sociedade, o que lhe confere caráter individualista frente a uma necessidade técnica. Assim, as

estratégias familiares são respostas dadas por cada família a fim de assegurar ao mesmo tempo a sua própria reprodução e a de sua exploração. Poder-se-ia dizer, simplificando, que o grande desafio dos agricultores brasileiros consiste em garantir um espaço aos numerosos 'herdeiros', um lugar de trabalho (muitas vezes a própria exploração familiar), sem que isso se torne técnica e economicamente inviável. (BRUMER et al., 1993, p. 205).

As unidades familiares são constituídas por um grupo econômico autônomo representado pela família, que procuram estabelecer suas estratégias de sobrevivência para o presente com perspectivas, também, para o futuro. Em geral, apresentam a tendência de uma forte centralização, buscando sua reprodução por meio de uma ligação econômica e afetiva com seus meios de subsistência. À medida que as condições materiais são produzidas, os laços afetivos e culturais são constituídos. Essas situações são estabelecidas no interior das unidades e visam assegurar a sucessão do patrimônio sociocultural.

Os vínculos afetivos são criados a partir da relação do trabalho do homem sobre a terra. Nessas famílias, o parentesco é compreendido, em sua temporalidade, marcando cada geração. A história de cada família evidencia os casamentos que se realizam e as condições que são criadas para a reprodução do grupo, resultando numa tradição. Para corroborar a afirmação, a cultura é vista como um complexo de signos e significações, incluindo a linguagem, que origina códigos de transmissão de valores e significados sociais (HARVEY, 2006).

A organização das atividades produtivas é um meio que assegura às famílias a possibilidade de resistir e se adaptar às transformações no parentesco. Woortmann (1995) valoriza a importância do estudo das relações de parentesco alicerçadas na reciprocidade, na descendência, nos comportamentos, nos laços consangüíneos, nas regras de sucessão, nos casamentos e outros. Aqui, reside a importância da preservação da identidade cultural de indivíduos ligados entre si por laços de parentesco e de consangüinidade, permitindo a reprodução de um modo de vida.

Brumer et al. (1993), a partir de suas pesquisas sobre as "explorações familiares" nas regiões de Leme (RS), Cariri da Paraíba (PB) e Ijuí (SP), discorrem sobre os vínculos comunitários na vida social desses produtores. Os produtores alegam 
que podem contar com o auxílio dos vizinhos tanto para ajuda pessoal quanto para a exploração. Todavia, advertem os autores, essa percepção envolve uma idealização local. “[...] Os sentimentos de solidariedade não excluem outros, mais individualistas, que envolvem a intolerância e as dificuldades nas relações de amizade." (BRUMER et al., 1993, p. 214).

Em razão das transformações estruturais na sociedade contemporânea, são cada vez mais difíceis o conhecimento e a compreensão da diversidade que envolve a essência da realidade do campo brasileiro, principalmente, num contexto em que todas as relações são explicadas, como via de regra, por códigos estritamente econômicos. Para Fernandes (2006, p. 29) “[...] a economia não é uma totalidade, ela é uma dimensão do território. Quando a produção de mercadorias é analisada como totalidade, fora da multidimensionalidade territorial, constitui-se numa análise extremamente parcial e, às vezes, equivocadas da realidade." Os fenômenos que envolvem o dinamismo social têm se tornado cada vez mais complexos, assim como os problemas que emergem desse processo evolutivo dependente e excludente.

Diante do exposto, o conjunto integrado de elementos, como suas tradições, seus valores morais, étnicos e religiosos, assegura a reprodução das comunidades rurais que constitui a construção de uma vida, de toda uma história que conjuga terra, trabalho, família e cotidiano. As famílias procuram descobrir e inventar caminhos para continuarem em seus territórios. Os moradores rurais organizam o seu território para realização de sua existência, construindo a sua história de vida. Essas discussões avigoram, ainda mais, a necessidade de conhecimento sobre as especificidades do modo de vida rural, a partir dos comportamentos comuns dos membros das comunidades e das numerosas características de crença.

\section{Os valores, as afetividades familiares na construção de um modo de vida}

A identificação de ocorrência geográfica das comunidades rurais dá-se em pequenas aglomerações mais ou menos concentradas e apresentam um alto índice de parentesco. As famílias estabelecem uma organização de vizinhança, criando um sentimento de localidade e identificação. Esses aspectos conferem às famílias, de uma determinada comunidade rural, uma identidade geográfica e social. A interação desses aspectos caracteriza um dos mundos manifestos e suas representações. Esse universo de 
representações é construído através do cotidiano dos moradores das comunidades rurais com a simplicidade de pessoas comuns que interagem com a própria comunidade, com as demais comunidades rurais e com a sociedade como um todo (relação de interconhecimento). Maldonato (2004) apresenta uma reflexão sobre os limites fundamentais de nossa capacidade de autocompreensão na tentativa de representar fenômenos complexos. Diante disso, esse autor salienta

Como todo mundo identificável, o mundo que permite a separação é uma resposta do ser e além disso é diferente do próprio Ser. Identificar os mundos manifestos mais conhecidos com o Ser não só desvaloriza os outros mundos manifestos que são igualmente claros, mostra também uma considerável falta de perspectivas. [...]. (MALDONATO, 2004, p. 37).

A análise teórico-prática se estrutura em torno do comportamento sociocultural, econômico e organizacional de comunidades rurais num dado território, porém não desprezando sua integração à sociedade global. Nesse segmento encontramos uma grande riqueza cultural, como tradições festivas, devoção aos Santos (predomínio da religião católica), valorização da família e dos costumes do lugar, enfim; um modo de vida preservado através de gerações. Nessas propriedades vivem homens simples, cuja história é construída à margem da realidade e das idéias dominantes, lutando para sobreviverem e resistirem às dificuldades de todo dia.

A comunidade torna-se o fundamento da vida em comum, representando uma construção social assentada em laços sangüíneos, na tradição e nos costumes, no trabalho e na fé. Em uma comunidade materializa-se a formação de personalidade, construída interativamente com o outro a partir dos sentimentos de vida e do parentesco (BUBER, 1987). Desse modo é que se apresenta o universo de uma vida simples e de muito trabalho, em que o trabalho, a terra e a família fazem parte de sua história. Uma história ou uma memória que é narrada e vivida pelas famílias que a protagonizam.

[...] as possibilidades que oferece o primado [do documento] - da oral sobre a escrita - os gestos acompanhados da palavra e, sobretudo, as relações com os espaços por eles criados. A memória tem esse duplo caráter de que falava Halbwachs [1950], exprime a auto-consciência individual e coletiva - do grupo, referindo-se às experiências, as idéias, aos sentimentos compartilhados. (GARCIA; SCARAMAL, 1995, p. 114).

Para Brumer et al. (1993) essas aglomerações não se constituem verdadeiramente em comunidade rural, no sentido antropológico do termo, mas uma 
forma de "[...] associação do meio rural com o núcleo urbano que a integra. [...] A cidade (ou município), sede da comunidade, preenche não somente suas funções propriamente urbanas, mas também outras funções de caráter indiscutivelmente rural. [...].” (BRUMER et al., 1993, p. 180, grifo dos autores).

A partir dessas orientações, a cultura torna-se uma chave para a compreensão sistemática de diferenças e semelhanças entre os homens. A noção de cultura considera não indivíduos isolados ou quaisquer características pessoais que possam possuir, mas comunidades de pessoas ocupando um espaço determinado, amplo e geralmente contínuo, além das numerosas características de crenças e comportamento comuns aos seus membros. Assim, em outras palavras, o conceito de cultura oferece um meio para classificar os seres humanos em grupos bem definidos, de acordo com características comuns verificáveis, e também, um meio para classificar áreas de acordo com as características dos grupos humanos que ocupam (WAGNER; MIKELL, 2003).

Supõe-se que alguns indivíduos se prendam a um certo saudosismo, às lembranças e experiências de um passado comprimido no presente como meio de garantir sua identidade e buscar suas raízes ou mesmo buscar identificar-se com o lugar, a casa, os objetos e com a experiência cotidiana comum como expressão de um forte vínculo social com o lugar em que se vive e manter um sentido palpável de continuidade. Provavelmente, essa reação pode ser interpretada como uma resistência ou mesmo traços de um sentimento valioso de pertencimento ao lugar, perante um contexto de relações sociais e econômicas dinâmicas.

O que, nas reflexões de Santos e Silveira (2001), refere-se à requalificação das relações humanas diante da empiricização do tempo pela construção técnica dos espaços na era das sociedades globalizadas. Todas as formas de representações estão submetidas ao desafio do tempo de giro e da dissolução das representações e dos valores tradicionais historicamente adquiridos. Entretanto, a dialética da evolução dos tempos da efemeridade provocou a reação de sentimentos e tendências opostas.

Quanto maior o sentimento de desconstrucionismo, tanto maior a necessidade de produzir algum tipo de verdade 'sólida', hábitos mais seguros e valores mais duradouros que possam resistir. Diante disso, acredita-se que o caminho da subjetividade, a busca da percepção e da presença dos bens culturais viabilizam a 
obtenção da síntese. Harvey (2006, p. 263) reforça esses argumentos afirmando que “[...] o retorno do interesse por instituições básicas (como família e a comunidade) e a busca de raízes históricas são indícios da procura de hábitos mais seguros e valores mais duradouros num mundo cambiante."

As famílias pioneiras das comunidades rurais do município de Catalão (GO) migraram para a região no final do século XIX (1899) e com um número expressivo de famílias de origem portuguesa, favorecidas pela construção da Rede Ferroviária Federal. O objetivo dessas famílias centrava-se em desmatar a sua propriedade e estabelecer condições para plantar e criar aves, suínos e um pequeno rebanho de bovinos, possibilitando o sustento familiar. A narrativa confere jus a propositura de Wanderley (2001), quando diz que os deslocamentos espaciais da família focam-se nos esforços para constituir um território, um lugar de vida e de trabalho capaz de guardar a memória da família e de reproduzi-la, o que garante a autonomia de seu modo de vida.

No período retratado, as necessidades de consumo das famílias eram poucas e boa parte de suas necessidades era obtida no próprio estabelecimento. Naquela época, as famílias eram grandes, os produtores ao nomearem algumas famílias contemporâneas a dos seus pais, salientaram que a menor família de seu conhecimento era composta por cinco, seis filhos, sendo comum famílias com oito, dez, quatorze filhos. O tamanho das famílias influenciava, também, nas construções habitacionais. Algumas dessas casas, remanescentes de um período em que as famílias eram grandes, foram reformadas, outras demolidas e até mesmo abandonadas (Figura 1).

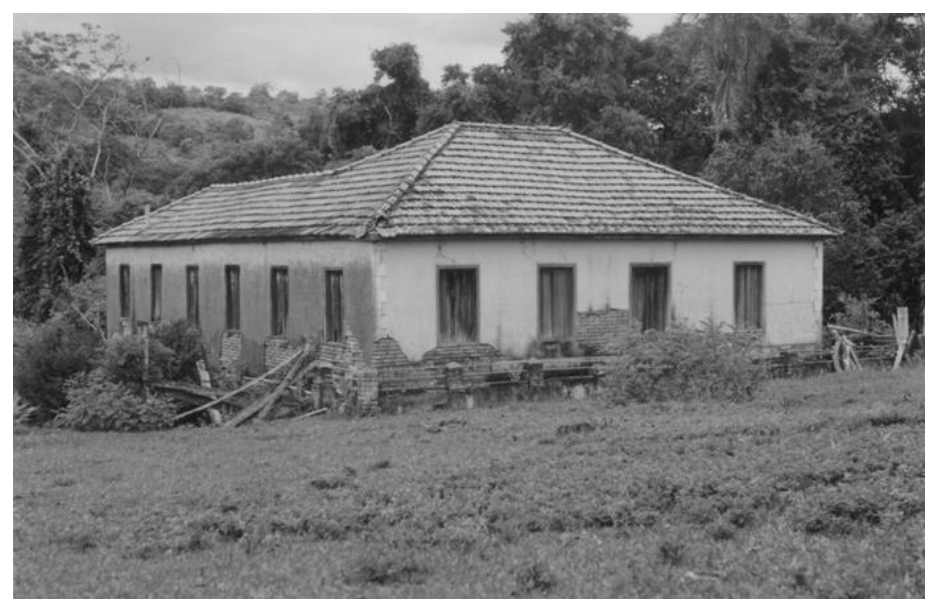

Figura 1 - Comunidade Coqueiro - Catalão (GO): casa construída no início do século XX. Autor: I. M. Ferreira, jan. 2001. 
Em termos de habitação rural, em geral, as casas construídas tinham as paredes altas, as janelas de madeira eram grandes, permitindo uma boa ventilação, o piso era de assoalho, as portas dos quartos davam para a sala de visita e para a salacopa, de maneira a aproveitar todo o espaço da construção. As cozinhas eram separadas por uma área livre, área de circulação. As pessoas que não fossem da família não tinham acesso ao corpo da casa, pois o costume era receber todas as visitas na cozinha. Os porões das casas eram utilizados (e ainda são) para estocar os gêneros alimentícios. A maioria das construções era feita pelos próprios moradores/proprietários, auxiliados pelos vizinhos, geralmente os irmãos.

Os filhos, desde pequenos, começavam a ajudar os pais. O trabalho na terra fazia parte de sua educação. Os filhos homens, à medida que adquiriam força e habilidade com as ferramentas, geralmente, a partir de nove anos de idade, acompanhavam os seus pais. Saíam ao alvorecer e voltavam ao pôr-do-sol, o que correspondia a, aproximadamente, dez, doze horas de trabalho diário, enquanto as filhas ajudavam as mães nas atividades domésticas. As pessoas não precisavam de muito para viver, era uma vida simples e de muito trabalho.

Com isso, a formação de valores e o conhecimento construído pela família dos produtores constituem informações importantes para a compreensão de sua lógica interna. A organização de espaços e a combinação de espécies e variedades vegetais, enfim, a organização da produção e da vida social são construídas com base em modelos de saber e de conhecimento do meio ambiente que representam mais que um conhecimento especializado para cultivar suas terras. Esse conhecimento é parte de um modelo mais amplo de percepção da natureza e dos homens. Com base nessas formulações Wagner e Mikesell (2003) consideram que

[...] quando as pessoas parecem pensar e agir similarmente, elas o fazem porque vivem, trabalham e conversam juntas, aprendem com os mesmos companheiros e mestres, tagarelam sobre os mesmos acontecimentos, questões e personalidades, observam ao seu redor, atribuem o mesmo significado aos objetos feitos pelo homem, participam dos mesmos rituais e recordam o mesmo passado. [...] Assim, a cultura também está assentada numa base geográfica, pois é provável que só ocorra comunicação regular e compartilhada entre pessoas que ocupam uma área comum. (WAGNER; MIKESELL, 2003, p. 28-29). 
Como aponta Woortmann e Woortmann (1997), esses valores são denominados 'ciência do concreto'. Nessa concepção, o significado do trabalho e o modelo de saber constituem uma forma de ver o mundo. Essas dimensões simbólicas incorporadas ao processo de trabalho promovem a construção, não apenas dos espaços agrícolas, mas também, dos espaços sociais. Corroborando com os autores, Fernandes (2006) esclarece que o espaço social está contido no espaço geográfico, criado originalmente pela natureza e transformado continuamente pelas relações sociais. Assim,

\begin{abstract}
o espaço geográfico contém todos os tipos de espaços sociais produzidos pelas relações entre as pessoas, e entre estas e a natureza, que transformam o espaço geográfico, modificando a paisagem e construindo territórios, regiões e lugares. Portanto, a produção do espaço acontece por intermédio das relações sociais, no movimento da vida, da natureza e da artificialidade, principalmente no processo de construção do conhecimento. [...]. (FERNANDES, 2006, p. 32).
\end{abstract}

Nesse sentido, a transmissão do saber para o trabalho faz-se no próprio trabalho, desde a infância. O conhecimento técnico, apreendido no decorrer da formação cultural dos descendentes, é visto como essencial para assegurar a sua própria reprodução. A reprodução social da família gera a expectativa da instalação de cada filho em um novo estabelecimento. O que confere, a terra, um conjunto de significados morais, de valores e de possibilidade de reprodução da estrutura social. O domínio do saber trabalhar permite ao homem a constituição de nova família, revigorando a relação entre trabalho, terra e família. Os casamentos realizados entre as famílias pioneiras das comunidades rurais ou pessoas conhecidas asseguram a reprodução da relação de vizinhança. O casamento dos filhos é um ritual sagrado para essas pessoas. Essa particularidade explica porque o grau de parentesco entre as famílias rurais é significativo.

A autonomia de seu modo de vida é assegurada pelo esforço para constituir um território, um lugar de vida e de trabalho capaz de guardar a memória da família e de reproduzi-la. A preocupação histórica, frente a um quadro marcado pela precariedade e instabilidade, assenta-se em garantir o consumo familiar e a integração ao mercado, o que fundamenta a constituição do patrimônio sociocultural. Para Wanderley (2001), a necessidade de atingir esses dois propósitos orienta a divisão do trabalho interna à família. Diante dessa realidade estrutural, sua experiência gerou um saber específico sendo transmitido através das gerações sucessivas. 
Com poucas exceções, os irmãos, os tios, os compadres, os primos e os pais formam a vizinhança. Os novos herdeiros possuem um grau de parentesco mais abrangente, resultado da união entre as várias famílias pertencentes a uma mesma comunidade rural ou mesmo de comunidades vizinhas. Sobremaneira, esse contexto justifica por que a maioria das famílias pesquisadas adquiriu a maior parte de sua propriedade fundiária através da herança. Quase sempre, as propriedades fundiárias são transmitidas para seus herdeiros em vida, assegurando a continuidade da tradição e memória cultural. O trabalho, o esforço e a honestidade são valores sempre exaltados como a maior virtude do homem.

Conforme os critérios de transmissão do patrimônio, privilegia-se os filhos homens que aprendem desde cedo a profissão dos pais. Sobre a questão da transmissão do patrimônio, Brumer et al. (1993, p. 191) colocam duas questões “[...] a primeira consiste em determinar quem, entre os numerosos herdeiros, assumirá a sucessão do patrimônio familiar; a segunda refere-se aos mecanismos de transmissão das explorações de uma geração a outra." Prevalece a tendência dos filhos homens, após o falecimento dos pais, comprarem as pequenas parcelas de terras subdivididas entre os herdeiros, pois, geralmente, são os filhos homens mais velhos que adquiriram conhecimento e experiência de gestão do estabelecimento. Para Abramovay (2000), isso significa que a continuidade da profissão paterna encontra-se vinculada ao conjunto de conhecimentos tácitos e não formais adquiridos pelos filhos no decorrer de sua educação.

Cabe à família e, principalmente, às mães a construção dos laços afetivos. Nesse contexto as mulheres casadas enfrentavam muitas dificuldades, como buscar água nos córregos e lenha para as necessidades da casa; cultivavam as hortaliças; socavam o arroz na mão (posteriormente essa atividade passou a ser feita pelos monjolos movidos a água); cuidavam dos filhos; faziam o polvilho; a farinha de mandioca; teciam; às vezes, costuravam para toda a família; cozinhavam para a família e para os 'companheiros'.

Os chamados 'companheiros' eram os agregados que moravam nas fazendas trabalhavam, também, do nascer ao pôr-do-sol, junto com o patrão e recebiam a 'féria' no final do dia. O pagamento era feito com produtos, como $1 \mathrm{~kg}$ de toucinho salgado ou 1 litro de banha de porco ou $1 \mathrm{~kg}$ de rapadura ou $1 / 2$ quarta de arroz com casca (medida 
equivalente a 20 litros - o que corresponderia, a mais ou menos quatro litros de arroz limpo) ou $1 / 2$ quarta de feijão ou $1 / 2$ quarta de café em coco ou fumo, e outros produtos, como sal, querosene, remédios que o fazendeiro comprava na cidade.

Nessas comunidades rurais praticava-se (e pratica-se) os chamados mutirões ou demão, que eram realizados aos sábados, tanto para o plantio, capina e/ou colheita, como para limpeza dos regos d'água (Figura 2). As mulheres, as fiandeiras e tecedeiras, reuniam-se para fiar (fazer os fios do algodão) e depois se reuniam, novamente, para tecer o tecido de algodão. Os mutirões contam com vários trabalhadores da vizinhança, a maioria parente. Conforme salientado por Woortmann e Woortmann (1997), a troca de dias de serviços entre os vizinhos, geralmente, encontram-se ligados por algum laço de consangüinidade. Observa-se que essa prática tornou-se uma necessidade funcional, o que Tedesco (2001) denomina de vínculos domésticos e trabalhos multivariados. "O mutirão não é propriamente um socorro, um ato de salvação ou um movimento piedoso; é antes um gesto de amizade, um motivo para folgança, uma forma sedutora de cooperação para executar rapidamente um trabalho agrícola.” (CANDIDO, 1998, p. 69).

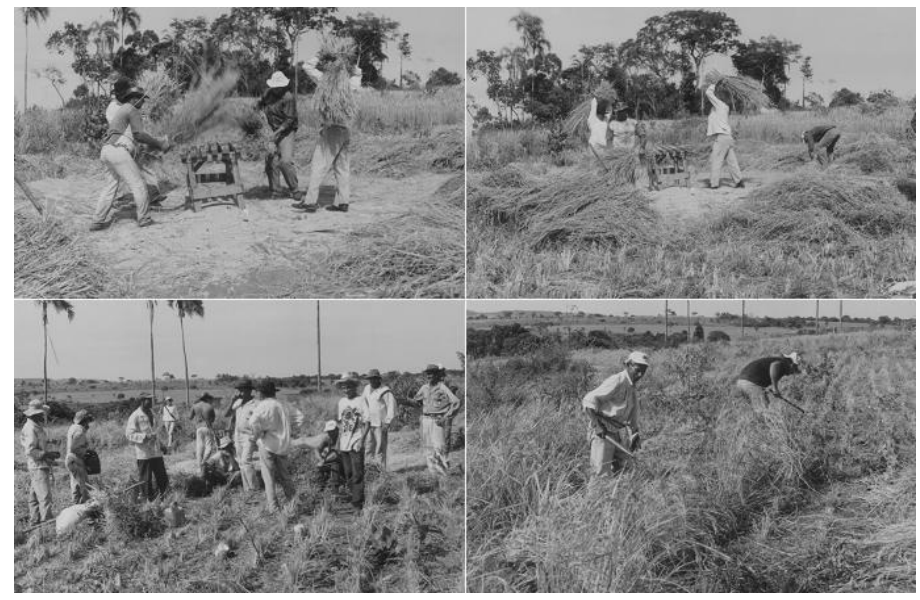

Figura 2 - Comunidade Mata Preta - Catalão (GO): demão na colheita de arroz. Autor: I. M. Ferreira, abr. 2005.

Outra expressão de ajuda mútua e solidariedade se dá na forma da 'traição'. Quando um vizinho percebia que alguém estava precisando de alguma ajuda, convocava os outros moradores da comunidade e vários trabalhadores (proprietários, companheiros) da vizinhança que se juntavam para realizar o serviço necessário. No final do dia faziam a tradicional festa. "A traição é uma terminologia regional utilizada 
para significar o caráter de surpresa da demão/mutirão.” (CANDIDO, 1998. p. 69). Na comunidade Coqueiro essa forma de trabalho é denominada como 'treição'.

Ainda hoje, as relações entre familiares e vizinhos está presente nas experiências de trabalho e nas afetividades familiares, caracterizando as formas de trocas de serviços, de produtos e de trabalho a 'meia', que recriam elementos de ajuda mútua e de solidariedade como fundamento de uma construção social. Essas relações encontram-se associadas com as formas contratuais de trabalho, na prestação de serviço temporário a fazendeiros da região. As diferenças socioeconômicas entre as unidades sugerem uma relação de interdependência entre os produtores da região, gerando uma organização social e cultural complexa. Essas relações não são, estritamente, econômicas, como a parceria, a troca de dias de trabalho, a demão e o arrendamento. Geralmente, os arrendamentos são pagos com a própria produção, exceto os produtos da horticultura.

Outro aspecto cultural que se destaca é a religiosidade. Os moradores dessas comunidades são, praticamente, todos católicos praticantes. Isso explica as festividades religiosas organizadas na região até hoje. As famílias das comunidades organizam suas festas no decorrer do ano, uma em homenagem a São Sebastião e a São José e a outra, em homenagem a Santo Antônio e ao Divino Espírito Santo. Esses eventos lhes permitem reunir para rezar e para rever os amigos, os parentes e os compadres. Elas ocorrem de maio a agosto, congregando várias famílias da comunidade e da região circunvizinha, chegando a ter, no final de semana, mais de 800 pessoas, enquanto que no decorrer da semana participam da festa de 50 a 200 pessoas.

Existem outras festas que são preservadas nas comunidades, como a Folia de São Sebastião (Mata Preta), a Fogueira de São João e a Encomenda de Almas na Semana Santa. A Folia de São Sebastião acontece de 17 a 20 de janeiro e, em cada ano a festa ocorre em uma casa diferente. Alguns participam da festa há mais de quinze anos. O festeiro escolhido ganha um ramalhete de flores e oferece o 'pouso', o transporte, as refeições e o cigarro. São treze foliões que percorrem todas as casas. Alguns moradores acompanham os foliões pelas demais sedes/propriedades. O carregador da bandeira organiza as visitas e os cantos e pede prendas - o que as pessoas quiserem doar, como bezerro, arroz, galinha, suíno, dinheiro, feijão, farinha, queijo, ovos, enfim de tudo. A comunidade aprecia essa festa e todos participam. 
A Encomenda de Almas é uma tradição que tem mais de cem anos e é feita durante três dias na Semana Santa, de quarta a sexta-feira, das 20h à 1h. O Sr. A. M. Duarte (informação verbal, comunidade Mata Preta, ago., 2004) conta que os encomendadores de alma (grupo formado por seis a doze pessoas) ao chegarem nas sedes tocam a matraca e o berra-boi [instrumentos rústicos usados para produzirem sons guturais] na porta da casa dos moradores - “está ocorrendo a desordem - é só para alertar o morador, ele não precisa se levantar." O grupo visita todas as casas. Primeiramente, eles fazem, todo ano, o levantamento de todas as casas por cada vertente e cada dia eles fazem um setor.

Os moradores só podem abrir as portas após os rezadores terminarem as rezas não podem abrir a porta antes porque os rezadores atiram pedras. Os antigos encomendadores de almas da região contavam que os moradores que saíam de suas casas para acompanhar os rezadores [depois deles já terem partido da sede] acabavam vendo as almas vestidas de branco atrás dos rezadores. Alguns ficavam com muito medo e voltavam para as suas casas [porém, o Sr. Arcanjo disse que ele mesmo nunca viu nenhuma alma!].

A Festa da Fogueira de São João é realizada no dia 24 de junho. Os festeiros convidam os familiares e amigos, em média oitenta a cem pessoas da comunidade participam. A festa representa uma tradição das famílias desses produtores e eles se sentem na obrigação de mantê-la. Para a Sra. L. O. Marques (informação verbal, comunidade Ribeirão, jul., 2003) esse costume iniciou-se com seus avós - são votos das famílias, pedindo que seus filhos nasçam com saúde. Primeiro é rezado o terço (Reza típica da religião Católica, que é composto pelas seguintes orações: Credo, Pai-Nosso, Ave-Marias, Glória, $1^{\circ}$ a $5^{\circ}$ Mistérios e Salve Rainha), em seguida acendem a fogueira, levantam a bandeira e começam a fazer os "Batizados de Fogueira de São João". Para o batizado é preciso um casal para serem os padrinhos e uma pessoa para representante de São João Batista - que representa a criança, é o momento mais importante da cerimônia.

O casal que será padrinho e o representante devem se ajoelhar em frente à fogueira com um prato esmaltado de cor branca, cheio de água e com uma vela acesa no centro. As três pessoas devem rezar um Pai Nosso, uma Ave Maria, uma Santa Maria, o Credo e, por último, uma Salve Rainha. Em seguida, o representante e depois os padrinhos colocam o dedo na água do prato, depois nas cinzas da fogueira e devem 
fazer o sinal da cruz com a água três vezes na testa da criança, pronunciando o nome do afilhado - eu te batizo em nome do Pai e do Filho, do Espírito Santo e de São João Batista (é a saudação da bênção entre padrinho e afilhado). A água do prato deve ser lançada em água corrente ou no pé do mastro de São João. E, por último, é servida a comida típica dessa data, ao som das sanfonas e violões.

A imposição de novas formas espaciais através do processo de urbanização contribui para desagregação de determinados valores. Todavia, a ruralização presente nas tradicionais festas religiosas e nas reuniões da comunidade pode ser compreendida como uma reação às mudanças impostas e um meio de reconstituição de suas tradições e das formas culturais comunitárias. Esses espaços construídos incorporam a história de gerações que produzem, não apenas sua subsistência, mas seu modo de vida, seus valores. A dinâmica de mercado dita os mecanismos que podem determinar seu destino. Todavia sua organização interna norteia suas estratégias de sobrevivência que, de um modo geral, tem sido assegurada pela multiplicidade de atividades desenvolvidas.

As novas estratégias produtivas, assentadas na multiplicidade de atividades desenvolvidas, representam a possibilidade de permanecerem na terra, para outros é a sua sentença. Diante desse contexto, os produtores das comunidades rurais têm procurado diversificar sua produção e comercializar diretamente parte da mesma, obtendo os rendimentos necessários, como estratégia para assegurar a reprodução de propriedade, a preservação da cultura e da autonomia. As feiras livres existentes no município viabilizam esse mecanismo.

\section{A terra, a família e o trabalho como unidade de produção e consumo}

Cada membro da família, pai, cônjuge, filhos e qualquer outro membro (forças marginais e não transferíveis) possuem seus deveres e obrigações diárias. Na realidade, há sempre muito trabalho para todos e os maiores problemas dizem respeito à remuneração do grupo familiar, ao baixo valor agregado aos produtos agrícolas, assegurando uma baixa renda agrícola aos membros da família, o que tem promovido a diminuição da população rural. Essa distribuição reflete, também, sobre os segmentos de produtores (agricultura empresarial moderna e pequena produção familiar) e produção na região. As pequenas propriedades rurais se reproduzem enquanto residuais de um tradicionalismo marcante na história brasileira (LAMARCHE, 1993). Esses estabelecimentos rurais caracterizam-se pelo predomínio do trabalho familiar, ou seja, a família é responsável pela administração e gerenciamento das atividades e também pela maioria do trabalho realizado na propriedade. 
A diversificação da produção de gêneros alimentícios é um meio de assegurar a reprodução familiar. Parte da produção, como hortaliças, grãos e criação de animais, destina-se ao consumo da unidade produtiva e a outra parte para o mercado. A produção para o próprio consumo é uma prioridade, uma vez que se destina à satisfação das necessidades do grupo familiar e representa um meio efetivo de rendimentos, sendo visto como indispensável a sua reprodução. Brumer et al. (1993) dizem que a diversificação é uma prática desejável para os pequenos produtores, evitando os riscos relacionados à dependência de uma única fonte de recursos, mas essa diversificação depende dos recursos de cada unidade produtiva.

Uma das medidas adotadas para reduzir os custos de produção tem sido a substituição da produção de grãos, como arroz e feijão, por cultivo que exija o uso de menos insumos externos, proporcione maiores rendimentos e menos concorrência. Assim, os pequenos produtores têm investido na produção de hortaliças para o mercado (tomate, repolho, pepino branco, principalmente, o alho) e/ou criação de gado leiteiro. A lida é essencialmente solitária, pesada e quase sempre na base da enxada. O leite é ordenhado manualmente (o uso da ordenha mecânica constitui uma exceção nessas comunidades) e a produção de queijo mineiro segue a tradição. As atividades no campo iniciam-se cedo, entre 5 e 6 horas, e finalizam ao anoitecer, procurando aproveitar o máximo possível do dia. Lamarche (1993) e Wanderley (2001) consideram evidente que as estratégias de reprodução, diante das condições modernas de produção, em grande parte, assentam-se na valorização dos seus recursos. Em combinação com uma produção diversificada para o mercado e para o autoconsumo são construídas as estratégias de sobrevivência do estabelecimento rural e da família.

Além da horticultura e da pecuária, em algumas unidades produz-se, de segunda a sábado, farinha de mandioca e polvilho (abr./ago.) para abastecer o comércio local (Figura 3). Há também preparo de farinha de milho, conservas (pequi, pimenta, jurubeba, guariroba), licores de frutas da estação, doces em calda e pedaços, geléias de mocotó, queijos, requeijão, aguardente, rapadura, açúcar mascavo, açafrão (jun./jul.), mel e várias quitandas. Como a produção é artesanal, o trabalho é pesado e demorado. Os doces, por exemplo, são feitos diariamente, conforme a natureza de cada um. Essa produção é comercializada, principalmente, nas feiras locais e em outras cidades próximas, junto com as hortaliças, aves, ovos e suínos. 


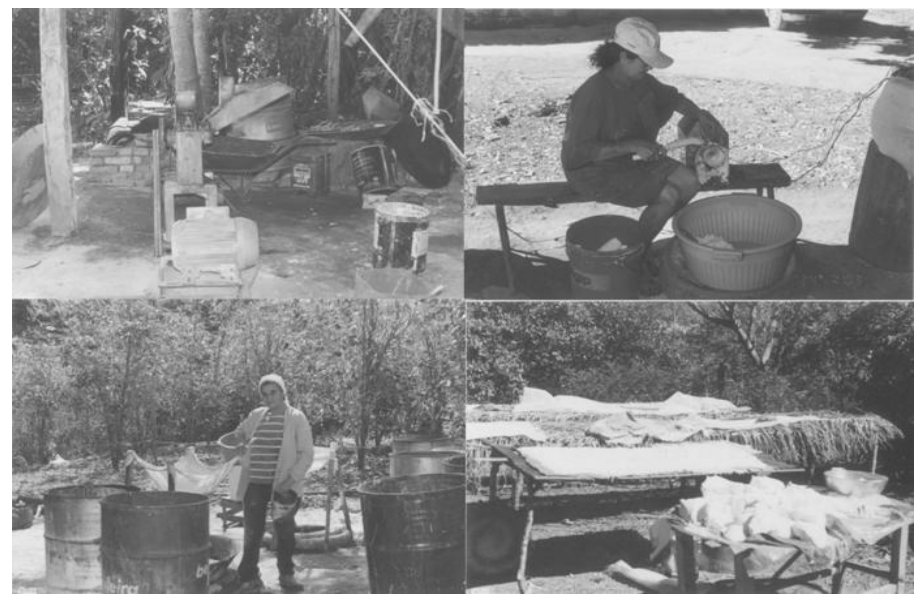

Figura 3 - Comunidades Coqueiro e Ribeirão - Catalão (GO): produção de polvilho. Autor: Ferreira, I. M. jul. 2003.

O mercado para produção artesanal/caseira tem crescido, assegurando uma demanda regular e, principalmente, uma renda específica para as mulheres. Está ocorrendo uma valorização do 'campo' - produtos mais naturais e saborosos. A produção para o mercado, também, segue a tradição das receitas de suas famílias. As feiras representam uma oportunidade para os produtores comercializarem, diretamente, seus produtos, aumentando a possibilidade de agregar valores. Tem crescido a demanda pela produção de produtos in natura e elaborados. Essas atividades têm assegurado uma complementação da renda para a população das comunidades rurais através de uma agregação de valor e eliminação dos intermediários, representando uma estratégia de sobrevivência.

As evidências empíricas sobre os aspectos socioculturais e econômicos mostram a importância dos trabalhos multivariados e as várias competências desses produtores. As estratégias adotadas e as formas de racionalidade possíveis enfrentam os desafios das situações de imprevisibilidades inerentes às condições naturais de cultivo e, principalmente, ao dinamismo do processo produtivo. Diante desse contexto, as tendências das comunidades rurais encontram-se vinculadas a um cenário de transformações, impondo a essa população o desafio constante de superação. É justamente esse dinamismo socioespacial que constitui os principais problemas relacionados a reprodução cultural. 


\section{Considerações finais}

As famílias das comunidades rurais pesquisadas caracterizam-se por apresentarem diferenças socioeconômicas e diversas estratégias de reprodução, como troca de dia de serviço, produção a meia e pagamento por dia de serviço entre as unidades produtivas que compõem cada comunidade. Em cada unidade produtiva prevalecem determinadas atividades comerciais que se destacam conforme, principalmente, a disponibilidade de terra e de recursos. Assim, tem-se as hortaliças, a produção de farinhas, polvilho, doces, a produção do queijo mineiro e a produção de leite, dentre outros. As desigualdades econômicas, o tamanho das propriedades, a força de trabalho doméstico disponível, o uso de tecnologia, os recursos, o perfil do produtor e as tradições de família justificam as diferentes estratégias produtivas dessas unidades familiares e sua maior ou menor inserção no mercado.

A maioria dos integrantes das unidades produtivas familiares mora no meio rural, porém, é uma realidade cada vez mais comum que parte da família trabalhe e estude nas cidades, como forma de complementar a renda familiar. A aposentadoria é outra renda não agrícola comum nas famílias rurais entrevistadas, representando $23,71 \%$ da amostra. Existe uma tendência em curso que aponta para o envelhecimento dessa população rural. Outra informação que confirma essa realidade refere-se à idade média dos chefes de família, 42,97\% estão na faixa etária entre 45 e 72 anos. Verificou-se, ainda, que em $10 \%$ das propriedades das comunidades rurais há moradores que vivem sozinhos (com idade entre 46 e 86 anos) e em 39\% vivem o casal ou o pai e um dos filhos homens (com idade entre 45 e 72 anos). (Informações obtidas pela pesquisa de campo - 2003 e na Secretaria Municipal de Saúde de Catalão - 2005). A limitada disponibilidade de terras das famílias rurais e a baixa remuneração do trabalhador rural tornam-se fatores principais de exclusão de muitos jovens produtores, o que coloca em risco a reprodução do patrimônio.

Diante do exposto, observa-se que as comunidades rurais definem-se pela homogeneidade das características socioculturais, morais, religiosas, étnicas, costumes, valores e pela heterogeneidade econômica, composição do grupo doméstico, tamanho da propriedade, recursos técnicos e gestão, assegurando a reprodução de formas particulares de produção e de sociabilidade que se renovam diante das novas exigências 
das políticas agrícolas em curso. Contudo, ainda enfrentam os antigos problemas, como a demanda irregular de mercado, os altos preços dos insumos agrícolas e os baixos preços de mercado para seus produtos.

Para enfrentar um fato novo, as famílias têm recorrido a uma multiplicidade de mecanismos e diversidade de competências, resultando em estratégias de reprodução das comunidades rurais. As famílias de uma comunidade lançam mão de uma disciplina de trabalho inerente a sua organização interna (unidade de produção, trabalho e convívio). O objetivo maior é adequar seu sistema produtivo às necessidades de reprodução social. Nesse ramo, como em qualquer outra atividade, os desafios são sempre uma realidade cotidiana. Essas famílias encontram-se profundamente inseridas em um território, lugar de vida e de trabalho, onde também estabelecem relações com outras categorias sociais e desenvolvem uma forma de sociabilidade específica no que se refere à maneira de ver e se relacionar com o tempo, com o espaço e com o meio ambiente, como também o modo de viver, de organizar a família, o trabalho e o cotidiano.

A comunidade rural é marcada pelos laços familiares e de parentesco inserida num contexto mais amplo de relações. Esse conjunto integrado de elementos viabiliza a reprodução do patrimônio sociocultural dessas famílias, como uma unidade de moradia, convívio, um quadro familiar e social de um gênero particular. Na tradição do trabalho são produzidos os saberes e a própria existência humana. Os pais e a comunidade na lida diária repassam aos seus filhos os conhecimentos que julgam importantes para sua formação, mecanismo que permite a construção de identidades. Com base nessas considerações, o espaço de vivência do homem do campo é compreendido como espaços geográficos singulares e plurais, autônomos e interativos que revelam seu modo de vida, de organização do trabalho e do espaço geográfico, de sua organização política e de suas identidades culturais, suas festas, seus conflitos e seus modos de organização diferenciados. Sua história está enraizada nos preceitos criados e reproduzidos pelos seus sujeitos a várias gerações.

\section{Referências Bibliográficas}

ABRAMOVAY, R. Paradigmas do capitalismo agrário em questão. São Paulo: Hucitec: 1992. 275 p. (Estudos Rurais, 12). 
Agricultura familiar e desenvolvimento territorial. Revista da Associação

Brasileira de Reforma Agrária - ABRA, Campinas, v. 29, n. 1, 2 e 3, p. 49-68, jan/ago. 1999.

Agricultura familiar e novas oportunidades à terra. Gazeta Mercantil. São Paulo, p. A-3, 30 nov. 2000. (Série Trajetória).

AMIN, S.; VERGOPOULOS, K. A questão agrária e o capitalismo. Tradução Beatriz Resende. 2. ed. Rio de Janeiro: Paz e Terra, 1986. 179 p. (Pensamento crítico, v. 15).

AMORIM FILHO, O. B. A evolução do pensamento geográfico e a fenomenologia. Sociedade \& Natureza, Uberlândia, n. 21 e 22, p. 67-87, jan/dez. 1999.

BUBER, M. Sobre comunidade. Tradução de Newton Aquiles von Zuben. São Paulo: Perspectiva. $136 \mathrm{p}$.

BRUMER, A. et al. A exploração familiar no Brasil. In: LAMARCHE, H. (Coord.). Agricultura familiar. Tradução Ângela M. M. Tigiwa. Campinas: UNICAMP, 1993. p. 179-234. (Coleção Repertórios).

CANDIDO, A. Os parceiros do Rio Bonito: estudo sobre o caipira paulista e a transformação dos seus meios de vida. 8. ed. São Paulo: Duas Cidades, 1998. 284 p.

CARLOS, A. F. A. O lugar no/do mundo. São Paulo: HUCITEC, 1996. 150 p.

CASTRO, I. E.; CORRÊA, R. L.; GOMES, P. C. C. (Org.). Geografia: conceitos e temas. Rio de Janeiro: Bertrand Brasil, 1995. 353 p.

CHAYANOV, A. V. La organización de la unidad económica campesina. Tradução Rosa María Rússovich. Buenos Aires: Nueva Visión, 1974. 342 p.

CORREAA, R. L.; ROSENDAHL, Z. (Org.). Introdução à geografia cultural. Rio de Janeiro: Bertrand Brasil, 2003. 224 p.

FERREIRA, I. M. O afogar das Veredas: uma análise comparativa espacial e temporal das Veredas do Chapadão de Catalão (GO). 2003. 242 f. Tese (Doutorado em Geografia) - Instituto de Geociências e Ciências Exatas, Universidade Estadual Paulista, Rio Claro.

FERNANDES, B. M. Os campos da pesquisa em educação do campo: espaço e território como categorias essenciais. In: MOLINA, M. C. (Org.). Educação do campo e pesquisa: questões para reflexão. Brasília: Ministério do Desenvolvimento Agrário, 2006. p. 27-39.

GARCIA, O. C.; SCARAMAL, E. Saber e cultura na família rural. In: ENCONTRO REGIONAL DA ASSOCIAÇÃO PROJETO DE INTERCÂMBIO DE PESQUISA 
SOCIAL EM AGRICULTURA - APIPSA, 5. , 1995, Goiânia. Anais... Goiânia: APIPSA, UFG, 1995. p. 110-120.

HARVEY, D. A condição pós-moderna. Tradução Adail Ubirajara Sobral; Maria Stela Gonçalves. 15. ed. São Paulo: Loyola, 2006. 339 p.

HESPANHOL, R. A. M.; COSTA, V. M. H. M. Produção familiar: perspectivas de análise e inserção na microrregião geográfica de Presidente Prudente. In: GERARDI, L. H. O.; MENDES, I. A. (Org.). Do natural, do social e de suas interações: visões geográficas. Rio Claro: Programa de Pós-Graduação em Geografia da UNESP; AGETEO, 2002. p. 157-172.

KAUTSKY, K. A questão agrária. Tradução João Antunes. Lisboa: Portucalense, 1972. 2 v.

LAMARCHE, H. (Coord.). Agricultura familiar: comparação internacional. Tradução Ângela M. N. Tijiwa. Campinas: Unicamp, 1993. v. 1, 336 p. (Coleção Repertórios).

MALDONATO, M. Não sabemos que não sabemos. Scientific American Brasil, São Paulo, n. 21, p. 32-37, fev. 2004.

MARTINS, J. S. A sociabilidade do homem simples. São Paulo: HUCITEC, 2000. 210 p. (Ciências Sociais, 43).

MARX, K. O capital: crítica da economia política. Tradução Reginaldo Sant’ Anna. 16. ed. Rio de Janeiro: Civilização Brasileira, 1998. 2 v.

MENDES, E. de P. P. A produção familiar em Catalão (GO): a Comunidade Coqueiro. 2001. 202 f. Dissertação (Mestrado em Geografia) - Instituto de Geografia, Universidade Federal de Uberlândia, Uberlândia.

MENDES, E. de P. P. A produção rural familiar em Goiás: as comunidades rurais em Catalão. 2005. 294 f. Tese (Doutorado em Geografia) - Faculdade de Ciências e Tecnologia, Universidade Estadual Paulista, Presidente Prudente, 2005.

Questões teóricas-metodológicas da produção rural familiar. Sociedade \& Natureza, Uberlândia, n. 26 a 29, p. 113-132, 2002/2003.

MENDES, E. de P. P.; CLEPS JÚNIOR, J. As transformações socioespaciais de Goiás: a incorporação de Goiás ao processo produtivo nacional (do século XVIII ao XX). Espaço em Revista, Catalão (GO), v. 7/8, p. 33-51, jan./dez. 2007.

MENDES, E. de P. P. A produção familiar no/do Cerrado: as comunidades rurais no município de Catalão (GO). In: SIMPÓSIO NACIONAL CERRADO, 9.; SIMPÓSIO INTERNACIONAL SAVANAS TROPICAIS, 2., 2008. Brasília. Anais... Brasília: Embrapa Cerrados, 7 p. 1 CD-ROM. ISBN 978-85-7075-041-9. 
MONTEIRO LOBATO, J. B. Jeca tatuzinho. 32. ed. Rio de Janeiro: Bloch, 1961. 12 p.

PRADO JÚNIOR, C. Contribuição para a análise da questão agrária no Brasil. In: ed. 1979).

A questão agrária no Brasil. 3. ed. São Paulo: Brasiliense, 1981. p. 15-85. (1.

História econômica do Brasil. 39. ed. São Paulo: Brasiliense, 1992. 364 p.

SANTOS, M. Metamorfose do espaço habitado. 3. ed. São Paulo: HUCITEC, 1994. A natureza do espaço. São Paulo: HUCITEC, 1996. 308 p.

SANTOS, M.; SILVEIRA, M. L. O Brasil: território e sociedade no início do século XXI. Rio de Janeiro: Record, 2001. 471 p.

TEDESCO, J. C. (Org.). Agricultura familiar: realidades e perspectivas. 3. ed. Passo Fundo: UPF, 2001. 405 p.

WAGNER, P. L.; MIKESELL, M. W. Os temas da geografia cultural. In: CORRÊA, R. L.; ROSENDAHL, Z. (Org.). Introdução à geografia cultural. Rio de Janeiro: Bertrand Brasil, 2003. p. 27-61.

WANDERLEY, M. N. B. Raízes históricas do campesinato brasileiro. In: TEDESCO, J. C. (Org.). Agricultura familiar: realidades e perspectivas. 3. ed. Passo Fundo: UPF, 2001. cap. 1, p. 21-56.

WOORTHMANN, E. F. Herdeiros, parentes e compadres. Herdeiros do sul e sitiantes do nordeste. São Paulo: Hucitec, Brasília: EDUnB, 1995. 336 p.

WOORTHMANN, E. F.; WOORTHMANN, K. O trabalho da terra: a lógica e a simbólica da lavoura camponesa. Brasília: EDUnB, 1997. 192 p.

Recebido para publicação em setembro de 2008 Aprovado para publicação em dezembro de 2008 